\title{
Barley varieties registered in the Czech Republic after the harvest of 2020
}

\author{
Vratislav Psota ${ }^{1 *}$, Olga Dvořáčková ${ }^{2}$, Markéta Musilová1 ${ }^{1}$ Milan Nečas ${ }^{2}$ \\ 1 Research Institute of Brewing and Malting, Mostecká 971/7, \\ 61400 Brno, Czech Republic \\ 2 Central Institute for Supervising and Testing in Agriculture, National \\ Plant Variety Office, Hroznová 63/2, 65606 Brno, Czech Republic \\ *corresponding author: psota@beerresearch.cz
}

\begin{abstract}
The study presents results of malting quality and agronomic characteristics obtained during testing of barley varieties in the Czech Republic. After the harvest of 2020, the following spring barley malting varieties were registered: Amidala, Focus, Greenway, KWS Jessie, LG Belcanto, and LG Stamgast. LG Stamgast was recommended for production of the beer with the protected geographical indication "České pivo". In addition, the non-malting spring barley variety RGT Gagarin was registered. Amidala, Focus, Greenway, KWS Jessie, LG Belcanto provided malt with the extract content over $83 \%$. These varieties also easily degraded nitrogenous substances. The value of the Kolbach Index ranged from 48.6 to $52.1 \%$. Diastatic power was at the optimal level. Degradation of cell walls was also optimal. Friability moved from 89 to $97 \%$ and $\beta$-glucan content in wort achieved satisfactory values of $65-170 \mathrm{mg} / \mathrm{l}$ in the given varieties. Wort quality, which is characterized by final attenuation, was at the above average to optimal level of 80.9-83.2\% in these varieties of spring barley. LG Stamgast showed lower values of proteolytic and cytolytic modification and lower values of final attenuation, which is required for the varieties recommended for the production of the beer with the protected geographical indication "České pivo".
\end{abstract}

Keywords: barley, variety, malting quality

\section{Introduction}

Between 2016 and 2020, an average of 1,128,000 tons of spring and 612,000 tons of winter barley were harvested in the Czech Republic annually. In 2020, the following malting varieties were represented in the propagating areas of barley: Bojos (25\%), Overture (12\%), Laudis 550 (11\%), KWS Irina (8\%), KWS Amadora (6\%), Spitfire (5\%), Francin (4\%), Manta (4\%), Bente (3\%), Malz (3\%), Ovation (2\%), and Sebastian (2\%) (CISTA, 2020).

In the Czech Republic, new barley varieties are registered under Act No. 219/2003 Coll. According to this act, the varietal trials are performed by a state administration body, which is the Central Institute for Supervising and Testing in Agriculture (further only CISTA). CISTA performs field and laboratory tests to determine differences, uniformity, stability and utility value according to methodologies set by the ministry.
A variety has a utility value if, in comparison with other registered varieties, in the sum of its characteristics, it represents, at least in one growing area, a clear benefit for cultivation or for its use or for products derived from them. If a variety has some excellent characteristics, some worse characters may be ignored. Yield and other yield parameters, resistance to diseases, resistance to lodging and parameters characterizing malt quality are evaluated in the tests required for the registration of a new variety.

\section{Material and Methods}

In the present study, the quality of spring barley varieties Amidala, Focus, Greenway, KWS Jessie, LG Belcanto, and LG Stamgast and the quality of the RGT Gagarin, which was registered as non-malting, was assessed (Table 1). 
Seed samples were supplied by CISTA. The barley varieties were assessed according to the Methodology of Barley Utility Value Testing (Dvořáčková, 2019).

\section{Selection of the testing sites}

Grain samples of the tested varieties were collected annually from four testing sites (Psota et al., 2021). The standard varieties exhibited the optimal content of nitrogenous substances (10.2-11.0\%) (Psota and Kosař, 2002). The aim was to ensure that the identified technological parameters were not affected by low or, conversely, high contents of nitrogenous substances in the grain.

\section{Malting and malt analyses}

The malting quality of Focus and Greenway was evaluated after testing conducted between 2017 and 2020 based on the analyses of 16 malt samples. Amidala, KWS Jessie, LG Belcanto, and LG Stamgast were analysed after three-year testing performed between 2018 to 2020 and 12 malt samples of these varieties were analysed.

Grain samples $(0.5 \mathrm{~kg})$ were malted in the micromalting plant of the KVM company (CR). The method traditionally used in the Research Institute of Brewing and Malting, which is almost identical with the MEBAK method (2011), was used for laboratory malting. Only the grain fraction over $2.5 \mathrm{~mm}$ was malted.

Steeping was conducted in a steeping box. The temperature of both water and air was kept at $14.0^{\circ} \mathrm{C}$. The length of steeping was 5 hours on the first day and 4 hours on the second day. On the third day, the water content in the germinating grains was adjusted to the value of $45 \%$ by steeping or spraying.

Germination was conducted in a germination box. The temperature during germination was $14.0{ }^{\circ} \mathrm{C}$. The total time of steeping and germination was $144 \mathrm{~h}$.

Kilning was performed in a single-floor electrically heated kiln. The total kilning time was $22 \mathrm{~h}$, prekilning was performed at $55{ }^{\circ} \mathrm{C}$, the kilning temperature was kept at $80^{\circ} \mathrm{C}$ for 4 hours.

The quality of the malt samples was assessed based on the parameters given in the Malting Quality Index (MQI) (Psota and Kosař, 2002) and characteristics given in the application for the protected geographical indication (PGI) “České pivo” (Commission Regulation, 2008).

In the course of the above mentioned tests, malting quality was determined according to the methods released by MEBAK (2011) and EBC Analysis Committee (2010). The methods used are listed in Table 2.
Table 1 The registered barley varieties after the harvest of 2020

\begin{tabular}{|l|l|}
\multicolumn{1}{|c|}{ Variety / Code } & \multicolumn{1}{|c|}{ spring barley } \\
\hline Amidala & \multicolumn{1}{c|}{ maintainer / Agent in the CR } \\
\hline NORD 16/2320 & NORDSAAT Saatzucht GmbH \\
\hline Focus & SAATEN - UNION CZ s.r.o. \\
\hline SC 101-12E & SECOBRA Recherches \\
\hline Greenway & SOUFFLET AGRO a.s. \\
\hline NOS 111.317-63 & Nordic Seed A/S \\
\hline KWS Jessie & SELGEN, a.s. \\
\hline KWS 163084 & KWS LOCHOW GMBH \\
\hline LG Belcanto & SOUFFLET AGRO a.s. \\
\hline LGBN15018-36 & Limagrain Europe \\
\hline LG Stamgast & Limagrain Central Europe Cereals, s.r.o. \\
\hline LGBHE4111 & Limagrain Europe \\
\hline \multicolumn{1}{|c|}{ spring barley } & Limagrain Central Europe Cereals, s.r.o. \\
\hline RGT Gagarin & \multicolumn{1}{c|}{ non-malting varieties } \\
\hline RP17015 & Société RAGT 2n \\
\hline
\end{tabular}

\section{The agronomic characteristics}

The agronomic characteristics of Amidala, KWS Jessie, LG Belcanto, LG Stamgast, and the RGT Gagarin, were assessed upon 8 experiments in maize testing area, 20 experiments in sugar-beet and cereal testing areas and 5 experiments in potato and forage testing areas. For Focus and Greenway, 10 experiments were conducted in maize testing area, 27 experiments in the sugar-beet and cereal testing areas and 8 experiments in potato and forage testing areas.

\section{The following parameters were assessed in the studied varieties:}

- yield of grain at the standard $14 \%$ moisture content. Yield of grain and yield of grain over $2.5 \mathrm{~mm}$ in spring barley in terms of the response of the varieties to the soil and weather conditions and suitability of the use of grain for malting are assessed within the production area (maize testing area, sugar-beet testing area, cereal testing area, potato testing area, forage testing area) (Psota et al., 2021);

- agronomic data (time to heading, maturity, straw length, resistance to lodging);

- resistance to diseases such as powdery mildew of barley (Blumeria graminis), leaf rust of barley (Puccinia hordei), the complex of leaf spots (Pyrenophora teres), scald of barley (Rhynchosporium secalis), head blight of barley (Fusarium graminearum, Fusarium culmorum, Microdochium nivale, etc.) and physiological leaf spots of barley (non-specific leaf spots);

- grain quality parameters (thousand grain weight and sieving test). 


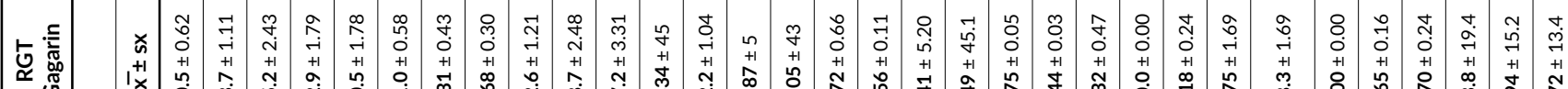

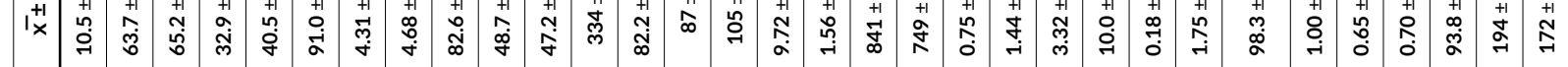

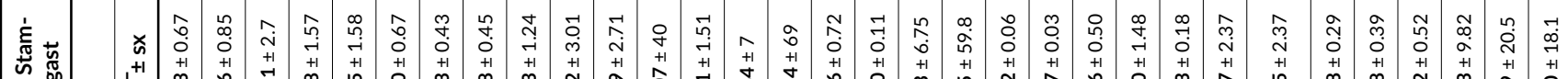

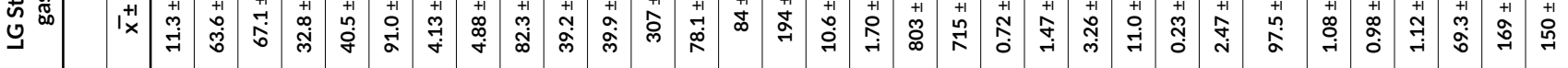

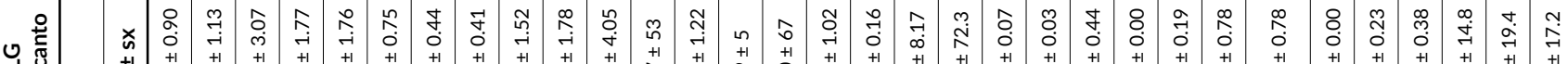

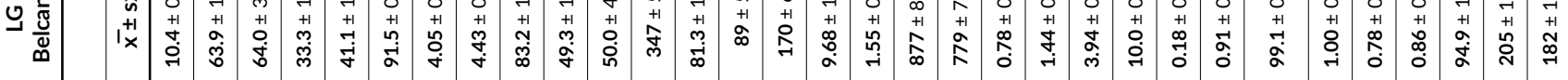

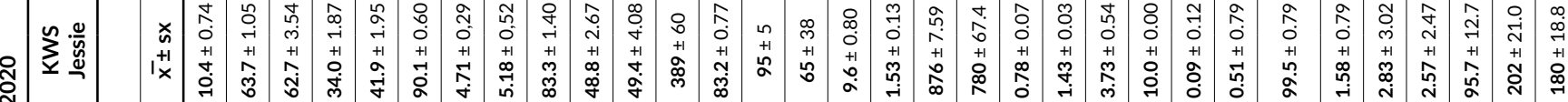

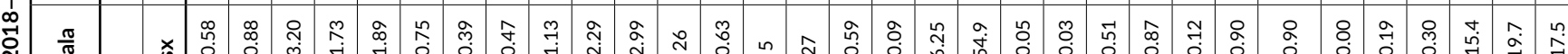

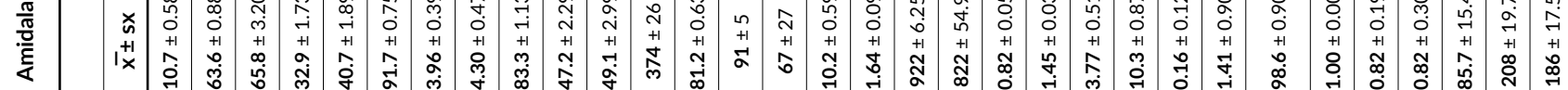

(1)

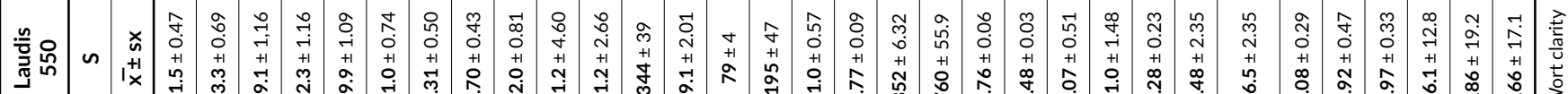

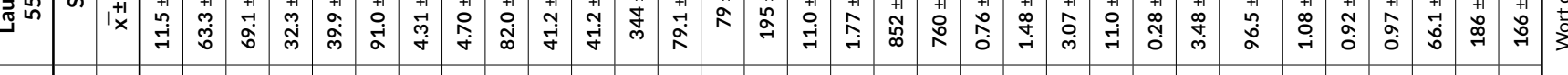

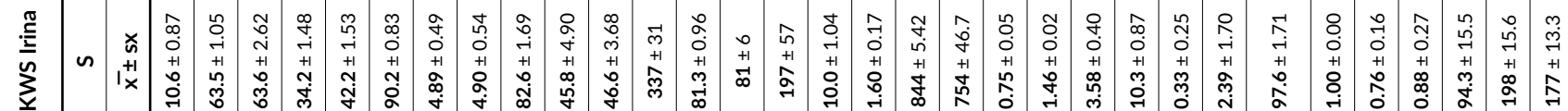

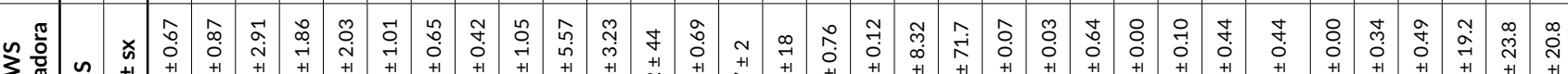

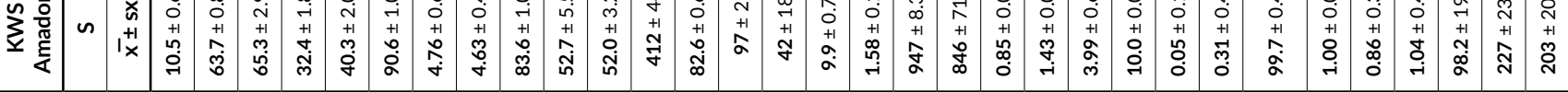

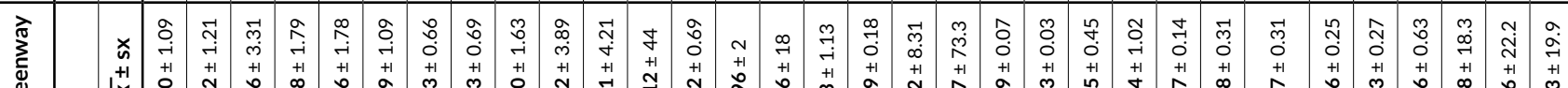

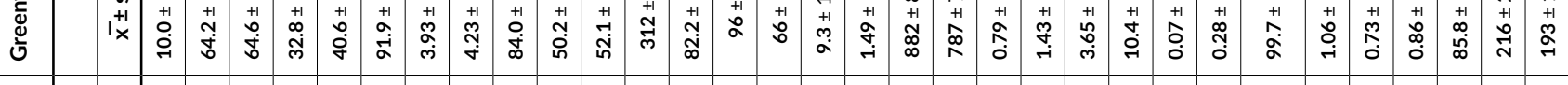

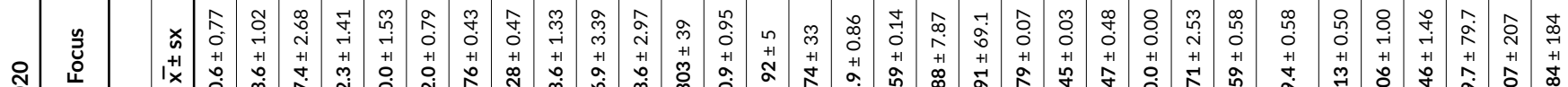

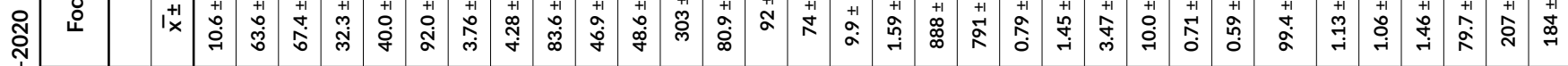
ลे

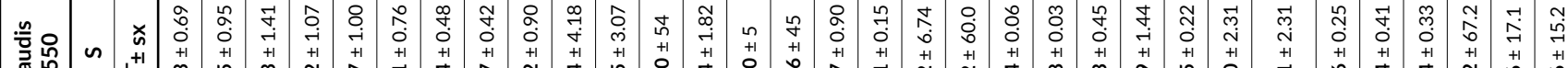

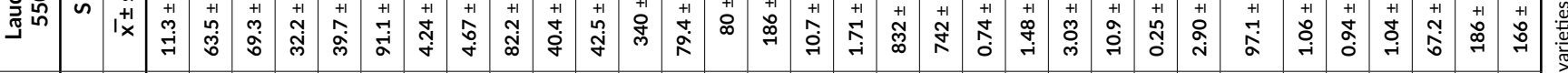

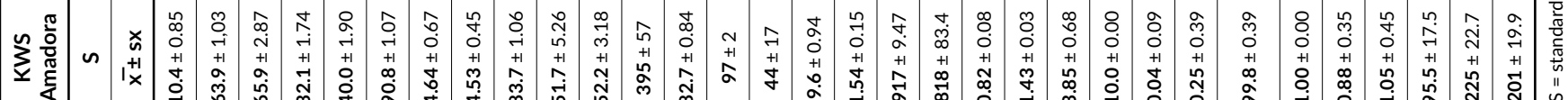

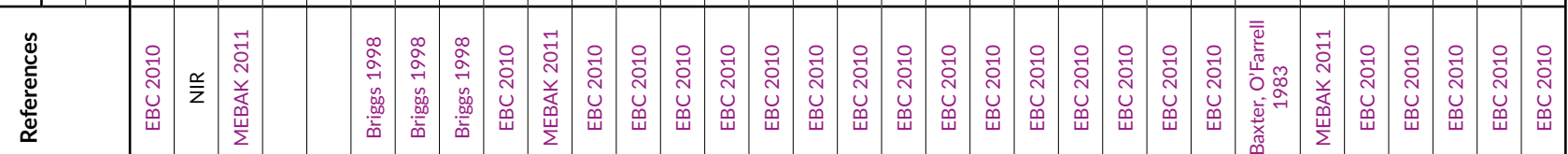

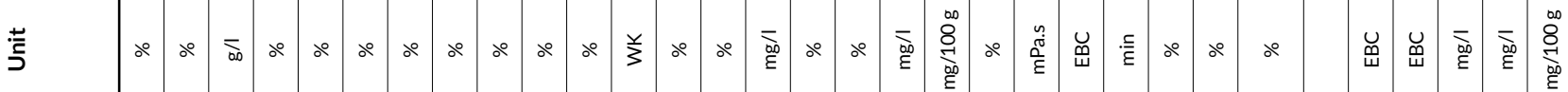

$\frac{\overleftarrow{4}}{4}$

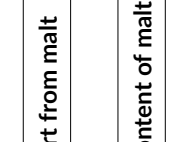

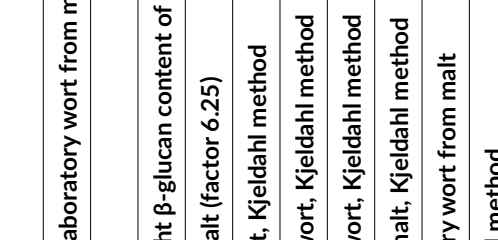

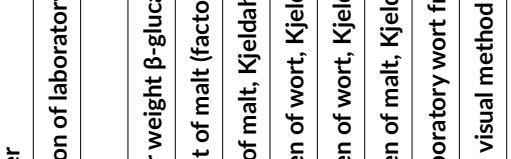

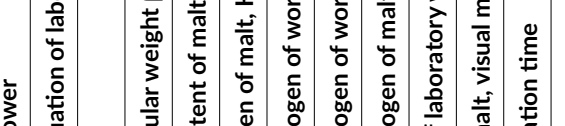

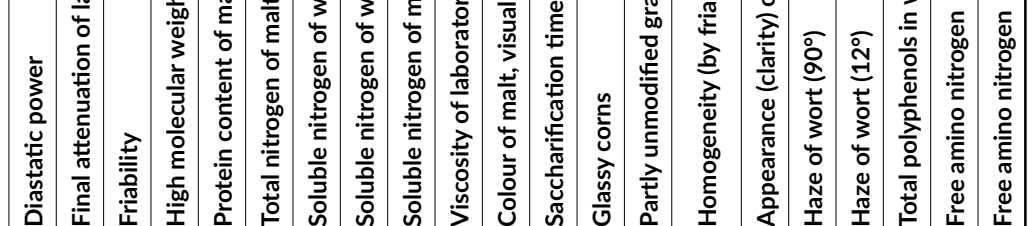

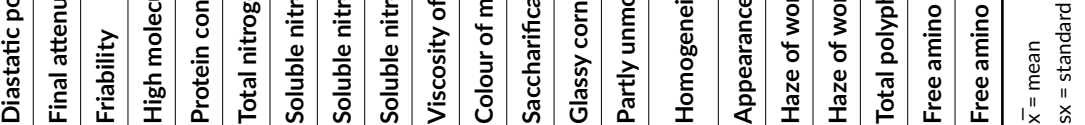


The experiments were established in two variants of growing: untreated and treated.

\section{N - untreated variant:}

- disinfectant - affective against loose smut of barley, barley leaf stripe, leaf spots (primary infection),

- basic dosage of nitrogen,

- without fungicidal treatment.

\section{T - treated variant:}

- disinfectant - affective against loose smut of barley, barley leaf stripe, leaf spots (primary infection),

- basic dosage of nitrogen,

- fungicide against stem-base diseases (as necessary) and against foliar and ear diseases (first treatment to the end of shooting, the other at the beginning of ear heading and before anthesis).

The total nitrogen dosage varied between 20 and $70 \mathrm{~kg}$ of pure nutrients per hectare depending on a previous crop and locality.

The utility value of the non-malting variety is only given in Table 3 without any verbal description.

\section{Results}

The quality of malt and wort samples produced from the tested varieties was evaluated using the characteristics included in the MQI and the application for the PGI "České pivo" (Table 2).

The yield, resistance to diseases and other agronomic characteristics of the malting varieties and the non-malting variety RGT Gagarin are given in Table 3.

The malt extract yield and the values of the other studied parameters were achieved by the varieties listed below at satisfactory to optimum content of nitrogenous substances in the non-malted grain. It can be assumed that other than optimal or almost optimal content of the nitrogenous substances in the non-malted grain will result in a change of these values.

For the varieties recommended for the production of the beer with the PGI "České pivo", lower levels of proteolytic and cytolytic modification and lower levels of wort fermentation are required. Of the newly registered varieties, only LG Stamgast met the conditions stated in the application for the PGI “České pivo” (Commission Regulation, 2008), as also confirmed by the results of the evaluation of malt and wort of the studied varieties.

The content of nitrogenous substances in non-malted grain ranged from 10.0 to $11.3 \%$. The obtained malts of spring barley varieties showed an extract content ranging from $82.3 \%$ for LG Stamgast to $84.0 \%$ for variety Greenway.

Proteolytic modification characterized by the Kolbach Index ranged widely from 39.9\% (LG Stamgast) to $52.1 \%$ (Greenway). The varieties Greenway and LG Belcanto showed strong proteolytic modification between 52.1 and $50.0 \%$. Soluble nitrogen in wort ranged from 803 to $922 \mathrm{mg} / \mathrm{l}$ in the monitored varieties. Amidala exhibited the highest soluble nitrogen levels. Apart from LG Stamgast, the other monitored malting varieties had an average content of free amino nitrogen (further only FAN) above the level of $200 \mathrm{mg} / \mathrm{l}$. FAN formed more than $20 \%$ of soluble nitrogen in all monitored varieties. The largest quantity $(25.0 \%)$ was recorded in Greenway.

Relative extract at $45{ }^{\circ} \mathrm{C}$ which characterizes mainly the activity of cytolytic and proteolytic enzymes, ranged from 39.2\% in LG Stamgast to 50.2\% in Greenway. The activity of amylolytic enzymes hydrolysing starch, mainly $\beta$-amylase, was at the optimal level. The value of diastatic power varied from 303 to $389 \mathrm{WK}$ un. Depending on the level of final attenuation, the quality of wort varied widely. KWS Jessie had the highest value of the final attenuation (83.2\%) and LG Stamgast the lowest one (78.1\%). The values of cytolytic modification also widely ranged. The variety LG Stamgast showed the lowest percentage of friability $(83.6 \%)$ and the highest content of $\beta$-glucans in wort (194 mg/l). In other varieties, especially in Greenway, the levels of cytolytic modification were better. The cell wall degradation in Greenway was high (97\%) and the $\beta$-glucan content low ( $66 \mathrm{mg} / \mathrm{l}$ ).

The colour of the wort in the studied varieties ranged from 3.3 to 3.9 EBC un.; this reflected the strong proteolytic modification of Amidala, Focus, Greenway, KWS Jessie, and LG Belcanto. Amidala and LG Belcanto always provided clear wort while opalescent wort was also recorded in the other varieties. The nephelometrically determined wort haze was low in all the studied spring barley varieties, except for KWS Jessie, where the average values above $2.6 \mathrm{EBC}$ un. were found.

Amidala, the variety bred in Germany, provided, at the optimal content of nitrogenous substances $(10.7 \%)$ in the non-malted grain, malt with the optimal level of the amylolytic modification. Extract content was $83.3 \%$ and diastatic power $374 \mathrm{WK}$ un. Intensity of proteolytic modification was satisfactory with the Kolbach Index 49.1\%. Cytolytic modification was at the optimal level (friability 91\%; $\beta$-glucan content in wort $67 \mathrm{mg} / \mathrm{l}$ ). The composition of wort was satisfactory (final attenuation $81.2 \%$ ) and clear in all cases. The benefit of the Amidala lies in its higher soluble nitrogen content (922 mg/l) and high FAN 
Table 3 Important agronomic characteristics

\begin{tabular}{|c|c|c|c|c|c|c|c|c|c|c|c|c|c|c|c|}
\hline \multirow[b]{3}{*}{ Variety } & \multirow[b]{3}{*}{$\begin{array}{l}\stackrel{\vec{n}}{\tilde{D}} \\
\stackrel{ \pm}{=}\end{array}$} & \multicolumn{5}{|c|}{ 2017-2020 } & \multicolumn{9}{|c|}{ 2018-2020 } \\
\hline & & \multicolumn{5}{|c|}{ spring barley } & \multicolumn{9}{|c|}{ spring barley } \\
\hline & & 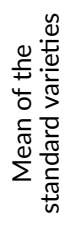 & 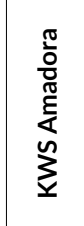 & 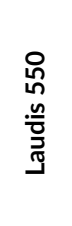 & 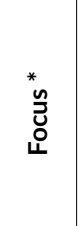 & 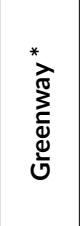 & 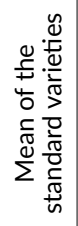 & 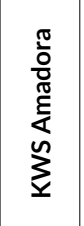 & 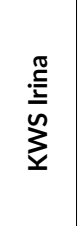 & 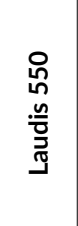 & 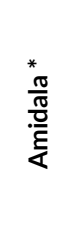 & 苋 & 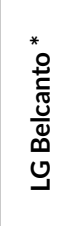 & 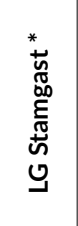 & 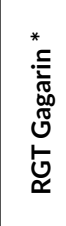 \\
\hline Grain yield (t/ha) & & t/ha & S & $S$ & & & & $S$ & $S$ & $S$ & & & & & \\
\hline \multirow{2}{*}{ maize testing area } & $\mathrm{N}$ & 5.93 & 5.96 & 5.89 & 6.32 & 6.30 & 6.33 & 6.25 & 6.47 & 6.28 & 6.67 & 6.76 & 6.98 & 6.62 & 6.81 \\
\hline & $\mathrm{T}$ & 6.23 & 6.29 & 6.18 & 6.68 & 6.71 & 6.65 & 6.61 & 6.85 & 6.48 & 6.87 & 7.05 & 7.29 & 6.93 & 7.29 \\
\hline \multirow{2}{*}{$\begin{array}{l}\text { sugar-beet and cereal } \\
\text { testing areas }\end{array}$} & $\mathrm{N}$ & 7.14 & 7.17 & 7.11 & 7.51 & 7.42 & 6.98 & 6.96 & 7.03 & 6.94 & 7.49 & 7.39 & 7.72 & 7.13 & 7.50 \\
\hline & $\mathrm{T}$ & 7.63 & 7.81 & 7.46 & 8.01 & 8.11 & 7.60 & 7.72 & 7.70 & 7.38 & 7.82 & 8.20 & 8.40 & 7.53 & 8.13 \\
\hline \multirow{2}{*}{$\begin{array}{l}\text { potato and forage } \\
\text { testing areas }\end{array}$} & $\mathrm{N}$ & 6.95 & 7.09 & 6.82 & 7.33 & 7.39 & 6.70 & 6.81 & 6.60 & 6.70 & 6.43 & 6.65 & 7.23 & 6.44 & 6.79 \\
\hline & $\mathrm{T}$ & 7.92 & 8.35 & 7.48 & 8.47 & 8.38 & 7.73 & 8.12 & 7.77 & 7.31 & 7.74 & 8.32 & 8.58 & 7.48 & 8.24 \\
\hline \multicolumn{16}{|l|}{ Grain over $2.5 \mathrm{~mm}$ (t/ha) } \\
\hline \multirow{2}{*}{ maize testing area } & $N$ & 4.74 & 4.50 & 4.98 & 4.59 & 4.66 & 5.17 & 5.27 & 4.90 & 5.35 & 5.70 & 5.75 & 5.47 & 5.72 & 5.12 \\
\hline & $\mathrm{T}$ & 4.88 & 4.76 & 5.01 & 5.09 & 4.99 & 5.36 & 5.51 & 5.23 & 5.34 & 5.71 & 5.76 & 5.69 & 5.99 & 5.63 \\
\hline \multirow{2}{*}{$\begin{array}{l}\text { sugar-beet and cereal } \\
\text { testing areas }\end{array}$} & $\mathrm{N}$ & 6.26 & 6.27 & 6.24 & 6.29 & 6.31 & 5.77 & 5.86 & 5.51 & 5.94 & 6.54 & 6.16 & 6.29 & 6.21 & 5.83 \\
\hline & $\mathrm{T}$ & 6.93 & 7.09 & 6.77 & 7.01 & 7.16 & 6.60 & 6.83 & 6.45 & 6.53 & 7.11 & 7.18 & 7.18 & 6.65 & 6.78 \\
\hline \multirow{2}{*}{$\begin{array}{l}\text { potato and forage } \\
\text { testing areas }\end{array}$} & $\mathrm{N}$ & 6.61 & 6.74 & 6.47 & 6.84 & 6.78 & 6.27 & 6.45 & 6.06 & 6.31 & 6.14 & 6.27 & 6.56 & 6.10 & 6.02 \\
\hline & $\mathrm{T}$ & 7.63 & 8.05 & 7.21 & 8.04 & 8.02 & 7.40 & 7.81 & 7.35 & 7.03 & 7.55 & 8.06 & 8.12 & 7.23 & 7.62 \\
\hline \multicolumn{16}{|l|}{ Agronomic data } \\
\hline straw length $(\mathrm{cm})$ & & & 68 & 72 & 71 & 71 & & 69 & 67 & 73 & 72 & 67 & 73 & 73 & 69 \\
\hline earliness of ripening** & & & 114 & 114 & 114 & 113 & & 114 & 115 & 114 & 115 & 113 & 115 & 115 & 115 \\
\hline $\begin{array}{l}\text { standing power } \\
\text { (lodging resistance) }\end{array}$ & & & 5.9 & 6.9 & 6.7 & 5.7 & & 5.5 & 7.1 & 6.5 & 5.8 & 6.3 & 6.5 & 6.8 & 7.1 \\
\hline \multicolumn{16}{|l|}{ Resistance to diseases } \\
\hline $\begin{array}{l}\text { powdery mildew of barley } \\
\text { (Blumeria graminis) }\end{array}$ & & & 8.9 & 8.8 & 7.7 & 8.8 & & 8.9 & 8.8 & 8.8 & 8.8 & 8.7 & 8.7 & 8.9 & 8.9 \\
\hline $\begin{array}{l}\text { leaf rust of barley } \\
\text { (Puccinia hordei) }\end{array}$ & & & 4.9 & 6.6 & 7.0 & 6.0 & & 4.9 & 6.7 & 6.4 & 7.0 & 6.0 & 6.1 & 7.4 & 6.5 \\
\hline $\begin{array}{l}\text { complex of leaf spots } \\
\text { (Pyrenophora teres) }\end{array}$ & & & 6.7 & 5.8 & 6.4 & 6.1 & & 6.9 & 6.4 & 5.9 & 6.2 & 6.1 & 6.4 & 6.3 & 6.1 \\
\hline $\begin{array}{c}\text { scald of barley } \\
\text { (Rhynchosporium secalis) }\end{array}$ & & & 7.1 & 7.2 & 8.1 & 7.8 & & 7.2 & 7.0 & 7.3 & 7.8 & 7.9 & 7.5 & 6.9 & 7.5 \\
\hline $\begin{array}{l}\text { head blight of barley } \\
\text { (Fusarium graminearum, F. culmo- } \\
\text { rum, Microdochium nivale etc.) }\end{array}$ & & & 7.0 & 6.9 & 6.3 & 6.6 & & 6.7 & 6.6 & 6.9 & 6.7 & 7.0 & 6.5 & 6.0 & 6.3 \\
\hline $\begin{array}{l}\text { physiological leaf spots } \\
\text { of barley }\end{array}$ & & & 8.1 & 5.6 & 8.2 & 7.7 & & 8.1 & 8.0 & 5.6 & 8.0 & 7.9 & 7.6 & 7.7 & 8.0 \\
\hline \multicolumn{16}{|l|}{ Grain quality } \\
\hline 1000 grain weight $(\mathrm{g})$ & & & 45 & 44 & 47 & 47 & & 45 & 44 & 44 & 50 & 44 & 47 & 47 & 46 \\
\hline $\begin{array}{l}\text { sieving fractions } \\
\text { over } 2.5 \mathrm{~mm}(\%)\end{array}$ & & & 87 & 88 & 84 & 85 & & 87 & 81 & 87 & 89 & 86 & 83 & 88 & 81 \\
\hline \multicolumn{16}{|c|}{$\begin{array}{l}1 \text { = fully lodging, fully attacked } 9=\text { non lodging, resistant to diseases } \\
\text { Weight of } 1000 \text { grains relates to sieving fractions over } 2.0 \mathrm{~mm} \text { at } 14 \% \text { moisture. } \\
\text { ** days from sowing to harvest maturity } \\
\text { Intensity: }\end{array}$} \\
\hline
\end{tabular}


content in wort (208 mg/l), which accounted for $23 \%$ of the soluble nitrogen in the wort. Amidala has a very good malting quality with the point evaluation of 8 .

According to the Common Catalogue of Varieties of Agricultural Plant Species, the variety is registered in Germany, France and Poland (European Commission, 2020).

Amidala is a malting, mid-early variety. Plants are medium high. The variety is medium resistant to lodging, medium resistant to stem breaking. It provides big grains and a medium high to high portion of sieving fractions above $2.5 \mathrm{~mm}$. It is resistant to powdery mildew of barley on the leaf (Blumeria graminis), medium resistant to leaf rust of barley (Puccinia hordei), medium resistant to the complex of leaf spots (Pyrenophora teres), resistant to scald of barley (Rhynchosporium secalis), medium resistant to fusarium (F. graminearum, F. culmorum, Microdochium nivale etc.) head blight of barley. The variety gives a very high yield of grain above $2.5 \mathrm{~mm}$ in the untreated variant of growing in maize and sugar-beet-cereal areas, high to very high in the treated variant of growing in a sugar-beet-cereal area, medium high to high in the treated variant of growing in a maize area, medium high in the treated variant of growing in a potato area, low in the untreated variant of growing in a potato area.

The utility value is given by the combination of a very high yield of sieving fractions above $2.5 \mathrm{~mm}$ in the untreated variant of growing in maize and sugar-beet-cereal areas, high to very high yield of sieving fractions above $2.5 \mathrm{~mm}$ in the treated variant of growing in a sugar-beet-cereal area and very good malting quality; therefore, compared to the registered spring barley varieties, the variety represents an obvious contribution.

Focus, the variety bred in France, provided, at the optimal content of nitrogenous substances $(10.6 \%)$ in the non-malted grain, malt with the optimal level of the amylolytic modification. The variety gave malt with a rich extract content $(83.6 \%)$ and the optimal level of diastatic power (303 WK un.). Intensity of proteolytic modification was also at the optimal level (Kolbach Index 48.6\%). Cytolytic modification was characterized by the optimal values. Degradation of cell walls characterized by friability was at the level of $92 \%$ and $\beta$-glucan content in wort at the level of $74 \mathrm{mg} / \mathrm{l}$. The composition of wort was satisfactory (final attenuation 80.9\%) and in most cases it was clear. The contribution of the variety Focus is a high content of FAN (on average $207 \mathrm{mg} / \mathrm{l}$ ) in wort, which accounted for $23 \%$ of the soluble nitrogen in the wort. Due to the achieved values in the monitored technological parameters, the variety had a very good malting quality with the point evaluation of 8 .
According to the Common Catalogue of Varieties of Agricultural Plant Species, the variety is registered in Denmark, Germany, France, and Finland (European Commission, 2020).

Focus is a malting, mid-early variety. The plant is medium high. The variety is medium resistant to lodging and medium resistant to stem breaking. It provides medium big grains and medium high to low portion of sieving fractions above $2.5 \mathrm{~mm}$. The variety is medium resistant to resistant to powdery mildew of barley on the leaf (Blumeria graminis), medium resistant to leaf rust of barley (Puccinia hordei), medium resistant to the complex of leaf spots (Pyrenophora teres), resistant to scald of barley (Rhynchosporium secalis), medium resistant to fusarium (F. graminearum, F. culmorum, Microdochium nivale etc.) head blight of barley. The variety rendered high yield of grain above $2.5 \mathrm{~mm}$ in the treated variant of growing in a potato area, medium high to high yield in the treated variant of growing in a maize area and in the untreated variant of growing in a potato area, medium high in both variants of growing in a sugar-beet-cereal area, low in the untreated variant of growing in a maize area.

The utility value is given by a combination of a very high yield of sieving fractions above $2.5 \mathrm{~mm}$ in the treated variant of growing in a potato area and very good malting quality; therefore, compared to the registered spring barley varieties, the variety represents an obvious contribution.

Greenway is a variety bred in Denmark. At a satisfactory content of nitrogenous substances $(10.0 \%)$ in the non-malted grain, it provided malt with the optimal amylolytic modification. The variety gave malt rich in extract $(84.0 \%)$ with the optimal level of diastatic power (312 WK un.). Intensity of proteolytic modification was high (Kolbach Index 52.1\%). Cytolytic modification was optimal. Wort exhibited a high level of the cell wall degradation (friability 96\%), this corresponded with the content of $\beta$-glucans in wort at the level of $66 \mathrm{mg} / \mathrm{l}$. The composition of wort was optimal (final attenuation 82.2\%). In most cases, the variety provided clear wort. The contribution of the variety Greenway is a high extract content and high content of FAN (on average $216 \mathrm{mg} / \mathrm{l}$ ) in wort, which accounted for $25 \%$ of the soluble nitrogen in the wort. Due to the achieved values in the monitored technological parameters, the variety had a very good malting quality with the point evaluation of 6 .

According to the Common Catalogue of Varieties of Agricultural Plant Species, the variety is registered in Denmark (European Commission, 2020).

Greenway is a malting, early variety with medium high plants. The variety is medium to less resistant to lodging, medium to less resistant to stem breaking. It 
provides medium big grains and a medium high to low portion of sieving fractions above $2.5 \mathrm{~mm}$. It is resistant to powdery mildew of barley on the leaf (Blumeria graminis), medium resistant to leaf rust of barley (Puccinia hordei), medium resistant to the complex of leaf spots (Pyrenophora teres), resistant to scald of barley (Rhynchosporium secalis), medium resistant to fusarium (F. graminearum, F. culmorum, Microdochium nivale etc.) head blight of barley. Yield of grain above $2.5 \mathrm{~mm}$ in the treated variant of growing in sugar-beet-cereal and potato areas was high, medium high in the treated variant of growing in a maize area and in the untreated variant of growing in sugar-beet-cereal and potato areas, low in the untreated variant of growing in a maize area.

The utility value is given by the combination of a high yield of sieving fractions above $2.5 \mathrm{~mm}$ in the treated variant of growing in sugar-beet-cereal and potato areas, earliness and very good malting quality; therefore, compared to the registered spring barley varieties, the variety represents an obvious contribution.

KWS Jessie, the variety bred in Germany. At an optimal content of nitrogenous substances $(10.4 \%)$ in the non-malted grain, it provided malt with the optimal amylolytic modification. The variety gave malt with the extract of $83.3 \%$ and diastatic power at the level of 389 WK un. Intensity of proteolytic modification was higher (Kolbach Index 49.4\%). Cytolytic modification was optimal. The cell wall degradation was high (friability 95\%) and $\beta$-glucan content in wort moved on average around $65 \mathrm{mg} / \mathrm{l}$. The composition of wort was optimal, (final attenuation $83.2 \%$ ). In a majority of cases, the variety provided clear wort. The contribution of the variety KWS Jessie lies in a high content of FAN (on average $202 \mathrm{mg} / \mathrm{l}$ ) in wort, which accounted for $23 \%$ of the soluble nitrogen in the wort. Due to the achieved values in the monitored technological parameters, the variety KWS Jessie had a very good malting quality with the point evaluation of 8 .

According to the Common Catalogue of Varieties of Agricultural Plant Species, the variety is registered in Germany, France, Slovenia, Luxembourg and Sweden (European Commission, 2020).

KWS Jessie is a malting, early variety. Plants are low, medium resistant to lodging, medium resistant to stem breaking. The variety provides medium big to small grains, medium high portion of sieving fractions above $2.5 \mathrm{~mm}$. KWS Jessie is resistant to powdery mildew of barley on the leaf (Blumeria graminis), medium resistant to leaf rust of barley (Puccinia hordei), medium resistant to the complex of leaf spots (Pyrenophora teres), resistant to scald of barley (Rhynchosporium secalis), medium resistant to fusarium (F. graminearum, F. culmorum, Mi- crodochium nivale etc.) head blight of barley. The variety achieved a very high yield of grain above $2.5 \mathrm{~mm}$ in the untreated variant of growing in a maize area and in the treated variant of growing in sugar-beet-cereal and potato areas, high in the treated variant of growing in a maize area and in the untreated variant of growing in a sugar-beet-cereal area, medium high in the untreated variant of growing in a potato area.

The utility value is given by the combination of a very high yield of sieving fractions above $2.5 \mathrm{~mm}$ in the untreated variant of growing in the maize and in the treated variant of growing in sugar-beet-cereal and potato areas, high yield of sieving fractions above $2.5 \mathrm{~mm}$ in the treated variant in a maize area and in the untreated variant in a sugar-beet-cereal area, earliness and very good malting quality. Therefore, compared to the registered spring barley varieties, the variety represents an obvious contribution.

LG Belcanto is a variety bred in the Netherlands. At the optimal content of nitrogenous substances $(10.4 \%)$ in the non-malted grain, it gave malt with the optimal level of the amylolytic modification. It provided malt with an extract at the level of $83.2 \%$ and diastatic power at the level of $347 \mathrm{WK}$ un. Intensity of proteolytic modification was at a higher level (Kolbach Index 50.0\%). Cytolytic modification was satisfactory. The cell wall degradation was optimal (friability 89\%) and $\beta$-glucan content in wort at the acceptable level (170 mg/l). The composition of wort was satisfactory (final attenuation 81.3\%). In all cases, the variety provided clear wort. The benefit of the variety LG Belcanto lies in a higher content of FAN (on average $205 \mathrm{mg} / \mathrm{l}$ ) in wort, which accounted for $23 \%$ of soluble nitrogen in the wort. Due to the achieved values in the monitored technological parameters, LG Belcanto had a very good malting quality with the point evaluation of 7 .

According to the Common Catalogue of Varieties of Agricultural Plant Species, the variety is registered in France (European Commission, 2020).

LG Belcanto is a malting, mid-early variety of a medium high to high type, with medium resistant to lodging, medium resistant to resistant to stem breaking. The grain is medium big, the portion of sieving fractions above $2.5 \mathrm{~mm}$ is medium high to low. The variety is resistant to powdery mildew of barley on the leaf (Blumeria graminis), medium resistant to leaf rust of barley (Puccinia hordei), medium resistant to the complex of leaf spots (Pyrenophora teres), medium resistant to resistant to scald of barley (Rhynchosporium secalis), medium resistant to fusarium (F. graminearum, F. culmorum, Microdochium nivale etc.) head blight of barley. The variety gave a very high yield of grain above $2.5 \mathrm{~mm}$ in both variants of growing in a sugar-beet-cereal area and in the 
treated variant of growing in a potato area, high in the untreated variant of growing in maize and potato areas, medium high to high in the treated variant of growing in a maize area.

The utility value is given by the combination of a very high yield of sieving fractions above $2.5 \mathrm{~mm}$ in both variants of growing in a sugar-beet-cereal area and in the treated variant in a potato area, high yield of sieving fractions above $2.5 \mathrm{~mm}$ in the untreated variant in maize and potato areas and very good malting quality. Therefore, compared to the registered spring barley varieties, the variety represents an obvious contribution.

LG Stamgast, the variety bred in the Czech Republic, provided malt with an acceptable extract content (82.3\%) and optimal level of the diastatic power (307 WK un.) at a suitable content of nitrogenous substances $(11.3 \%)$ in non-malted grain. Proteolytic modification was low (Kolbach Index 39.9\%). The cell wall degradation was at the satisfactory level of $84 \%$, but $\beta$-glucan content in wort $(194 \mathrm{mg} / \mathrm{l})$ was high. The composition of wort was very low (final attenuation 78.1\%). In most cases, the variety provided clear wort. Content of FAN (169 mg/l) in wort was at the medium level and formed $21 \%$ of soluble nitrogen in wort. The variety LG Stamgast has malting quality with a point evaluation of 5 . The variety fulfilled the requirements given in the application for PGI "České pivo" and it was recommended for the production of the beer with the protected geographical indication "České pivo".

LG Stamgast is a malting, mid-early variety of a midhigh to high type. The variety is medium resistant to lodging, medium resistant to resistant to stem breaking. Grain is medium big. The portion of sieving fractions above $2.5 \mathrm{~mm}$ is medium high. It is resistant to powdery mildew of barley on the leaf (Blumeria graminis), medium resistant to resistant to leaf rust of barley (Puccinia hordei), medium resistant to the complex of leaf spots (Pyrenophora teres), medium resistant to scald of barley (Rhynchosporium secalis), medium resistant to fusarium (F. graminearum, F. culmorum, Microdochium nivale etc.) head blight of barley. The variety achieved a very high yield of grain above $2.5 \mathrm{~mm}$ in the untreated variant of growing in a maize area, high to very high in the untreated variant of growing in a sugar-beet-cereal area, high in the treated variant of growing in a maize area, medium high in the treated variant of growing in a sugar-beet-cereal area, low in both variants growing in a potato area.

The utility value is given by the combination of a very high yield of sieving fractions above $2.5 \mathrm{~mm}$ in the untreated variant of growing in the maize area, high to very high yield of sieving fractions above $2.5 \mathrm{~mm}$ in the untreated variant in a sugar-beet-cereal area, high yield of sieving fractions above $2.5 \mathrm{~mm}$ in the treated variant in a maize area, medium resistance to resistance to leaf rust of barley and malting quality which fulfils the requirements for the production of beer with the PGI "České pivo". Therefore, compared to the registered spring barley varieties, the variety represents an obvious contribution.

\section{Conclusion}

In 2021 seven spring barley varieties were registered in the Czech Republic. RGT Gagarin was registered as a non-malting variety. The variety LG Stamgast fulfilled the requirements listed in the application for the PGI "České pivo" and was recommended for the production of the beer with the PGI “České pivo". LG Stamgast is characterized mainly by a low level of proteolytic modification and a lower level of final attenuation which is required for this type of varieties. Amidala, Focus, Greenway, KWS Jessie, and LG Belcanto belong to the varieties with high extract content, strong proteolysis and cytolysis and high content of FAN in wort.

\section{Acknowledgement}

Supported by the Ministry of Agriculture of the Czech Republic, institutional support MZE-R01918.

\section{References}

Act No. 219/2003 Coll., On the Marketing of Seed and Planting Material of Cultivated Plants and on the Amendment to Certain Acts.

Baxter, E.D., O'Farrell, D.D. (1983). Use of the Friabilimeter to Assess Homogeneity of Malt. Journal of the Institute of Brewing. 89, 210-214. https://doi.org/10.1002/j.2050-0416.1983.tb04169.x

Briggs, D.E. (1998). Malts and Malting. Blackie Academic and Professional, London, pp. 622-624. ISBN 100412298007

CISTA (2020). Summary of Entered Propagating Areas 1st part. Division of Seed and Planting Materials CISTA 2020.

Commission Regulation (2008). Publication of an Application pursuant to Article 6(2) of Council Regulation (EC) No 510/2006 on the Protection of Geographical Indications and Designations of Origin for Agricultural Products and Foodstuffs. Official Journal of the European Union C 16-22.

Dvořáčková, O. (2019). Metodika zkoušek užitné hodnoty - ječmen. ÚKZÚZ NOÚ, Brno. Available in Czech from: http://eagri.cz/public/ web/ukzuz/portal/odrudy/ registrace-odrud/metodiky-zkousek/

EBC Analytica, 2010: Analytica-EBC. 3.13 Moisture and Total Nitrogen in Barley by Near Infrared Spectroscopy, 4.3.1 Total Nitrogen of Malt: Kjeldahl Method, 4.2 Moisture Content of Malt, 4.3.2 Total Nitrogen of Malt: Dumas Combustion Method, 4.5.1 Extract of Malt: Congress Mash, 4.9.1 Soluble Nitrogen of Malt: Kjeldahl Method, 4.10 Free Amino Nitrogen of Malt by Spectrophotometry - 1997, 4.11.1 Fer- 
mentability, Final Attenuation of Laboratory Wort from Malt, 4.12.2 Diastatic Power of Malt by Segmented Flow Analysis, 4.15 Friability, Glassy Corns and Unmodified Grains of Malt by Friabilimeter, 4.16.2 High Molecular Weight $\beta$-Glucan Content of Malt and Malt Wort: Fluorimetric, 8.12 Total Polyphenols in Wort by Spectrophotometry, 9.29 Haze in Beer: Calibration of Haze Meters, Nüremberg: Fachverlag Hans Carl, pp. 794 ISBN 978-3-418-00759-5.

European Commission (2020). Common Catalogue of Varieties of Agricultural Plant Species -Version of 1 December 2020. Official Journal of the European Union C416: 1-12.
MEBAK (2011). Raw Materials: Barley; Adjuncts; Malt; Hops and Hop Products. 1 Barley: 1.5.3 Micromalting; Malz: 3.1.4.11 Maischmethode nach Hartong-Kretschmer VZ $45^{\circ} \mathrm{C}$. Collection of Brewing Analysis Methods of the Mitteleuropäische Brautechnische Analysenkommission (MEBAK), Freising-Weihenstephan, Germany. 2011. 341 p.

Psota, V., Kosař, K. (2002). Malting Quality Index. Kvasny prumysl, 48(6), 142-148. https://doi.org/10.18832/kp2002011

Psota, V. Dvořáčková, O., Musilová, M., Nečas, M. (2021). Barley and Malt. In: Psota, V. (ed.) Barley Year Book 2021. VÚPS Praha. ISBN 978-8086576-94-7 